\title{
versants
}

REVISTA SUIZA DE LITERATURAS ROMÁNICAS

Revista publicada bajo el auspicio del Collegium Romanicum

(Asociación de los Romanistas Suizos)

con el apoyo de la Academia Suiza

de Ciencias Humanas y Sociales

NÚMERO 63:3 (FASCÍCULO ESPAÑOL)

2016

TEORÍA/S

Número editado

por Bénédicte VAUTHIER

SLATKINE

GINEBRA

Difusión en Francia:

HONORÉ CHAMPION ÉDITEUR,

París 
Soutenu par l'Académie suisse des sciences humaines et sociales www.assh.ch

(C) 2016. Éditions Slatkine, Genève.

www.slatkine.com

Reproduction et traduction, même partielles, interdites.

Tous droits réservés pour tous les pays.

ISBN 978-2-05-102791-5 ISBN 978-2-05-102792-2

ISSN 0256-9645 


\section{Mundialidad hispánica y literatura de la migración}

Las solapas y reseñas de las obras de ficción contemporáneas de escritoras y escritores ${ }^{1}$ hispánicos que se «relocalizaron» ${ }^{2}$, sea por causa de un exilio o de una migración más planificada, suelen celebrar el carácter global de una literatura hispánica en expansión. Si está claro que tal apertura sólo puede regocijarnos, también es menester recordar que dicha literatura, escrita por autores que son a la vez de aquí y de allí, cuestiona directamente el concepto de literatura nacional, continental e hispánica al plantear numerosas preguntas. ¿Un texto escrito por una venezolana exiliada en España pertenecería acaso a la literatura europea? ¿Depende de la lengua en la que escribe o más bien de los temas tratados por el autor? ¿Habría sujetos específicos compartidos por estos escritores tan distintos? No es posible contestar a estas preguntas con una simple respuesta de pocas palabras sin caer en el maniqueísmo, ya que siempre depende de una clasificación literaria, es decir, de una organización basada en conceptos situados y, por consiguiente, subjetivos. Por tanto, intentaré demostrar aquí que hablar de literatura de la migración implica poner en tela de juicio los referentes culturales e identitarios que, en la mitología colectiva, fundan y mantienen nuestra historia literaria y cultural.

Desde luego estas cuestiones no son recientes, se han discutido desde hace muchos años en el espacio cultural canadiense, especialmente en el espacio francófono de ese país. Como indica D. Chartier, las revistas Dérivées o Vice versa han sido, desde los años 1970, portavoces de los nuevos discursos críticos y de las voces mestizas ${ }^{3}$. Asimismo, en Estados

\footnotetext{
${ }^{1}$ A lo largo de este texto, me referiré tanto a las escritoras hispanoamericanas como a los escritores originarios de esta región del mundo, empero, por cuestión de legibilidad, de aquí en adelante seguiré la regla de la predominancia del género gramatical masculino.

${ }^{2}$ Aunque este término no aparece en el diccionario de la RAE, se emplea en el ámbito de la economía para referirse al desplazamiento internacional de personas o empresas hacia otra estructura productiva. Lo usamos aquí para entender dichos desplazamientos de escritores como parte de un proceso de globalización desde la periferia al centro. Desde luego, su vigencia está condicionada a su uso deconstructivista, es decir, si sirve para cuestionar la misma idea de centro y las afirmaciones de los (neo)colonizadores hacia la unidad y la fijeza de un modelo de desarrollo y de cultura.

${ }^{3}$ Daniel Chartier, «Les origines de l'écriture migrante. L'immigration littéraire au Québec au cours des deux derniers siècles», Voix et Images, 27, 80, 2002, pp. 303-316.
} 
Unidos, el estudio de las obras de escritores inmigrantes y originarios de las diásporas permiten entender y reconocer la importancia del aporte de la literatura migrante para la historia de la literatura de ese país ${ }^{4}$. En el ámbito literario del «hispanoamericanismo», la situación es bastante distinta y, por ello, nos centraremos ahora en esta temática literaria que despierta un interés creciente. Nos detendremos primero en el paulatino y reciente despertar de esta cuestión en el hispanismo e hispanoamericanismo europeo; luego, nos centraremos en los rasgos definitorios de lo que ha venido a llamarse «literatura de la migración» y especialmente en las perspectivas de estudio que abren. En un tercer apartado, reflexionaremos sobre el sentido que puede cobrar la expresión de una cierta «mundialidad hispánica» y sobre las cuestiones poscoloniales que la producción y circulación de dichas obras implican.

\section{Un debate en construcción}

Desde hace unos diez años, han aparecido, paulatinamente, antologías que recogen textos escritos por autoras y autores latinoamericanos que viven en Europa. Una primera referencia podría ser Palabra de América publicado en 2004 por Seix Barral en la que se recopilan las intervenciones de los autores -todos masculinos- que participaron en el Primer Encuentro de Escritores Latinoamericanos en Sevilla en $2003^{5}$. Un poco más tarde, E. Andradi reunió en la antología Vivir en otra lengua (2010) catorce autores y autoras latinoamericanos que escriben en una lengua distinta de aquella que se habla en el país de acogida ${ }^{6}$. En cuanto a la poesía, en 2012 D. Bertini publicó en línea una antología de poetas argentinos residentes en Barcelona ${ }^{7}$, un trabajo que B. Del Pliego amplió, en cierto modo, al editar la antología de poesía Extracomunitarios. Nueve

\footnotetext{
${ }^{4}$ En este ámbito se habla, por ejemplo, de la literatura de la migración india o de la diáspora caribeña que se estudia en departamentos tan distintos como los de "Cultural Studies», «Postcolonial Studies» o "Commonwealth Studies».

${ }^{5}$ Roberto Bolaño et al., Palabras de América, Barcelona, Seix Barral, 2004.

${ }^{6}$ Esther Andradi (ed.), Vivir en otra lengua. Literatura latinoamericana escrita en Europa, Alcalá La Real, Alcalá Grupo Editorial, 2010.

7 Dante Bertini (ed.), TransAtlánticos. Poetas argentinos de/en Barcelona, Barcelona, Consulado General de la República Argentina, 2012, http://www.consuladoargentinobarcelona.com/ESPECIALES/ Transatlanticos [01-04-2016].
} 
poetas latinoamericanos en España $(2013)^{8}$. En cuanto a la crítica literaria cabe destacar que la literatura de la migración latinoamericana está ya muy desarrollada en Norteamérica donde es, incluso, asignatura universitaria y tema de historias literarias -entre las cuales se pueden citar las de N. Kanellos ${ }^{9}-$. Sin embargo, en el área hispanista europea, esta cuestión sigue siendo poco discutida aunque los intercambios literarios entre España y América Latina se remontan a los orígenes y a la formación misma de estos corpus literarios - una paradoja que ya desarrollé en otro lugar ${ }^{10}$.

Un primer artículo fundamental en estas reflexiones, es el titulado «Los que son de aquí. Literatura e inmigración en la España del siglo XXI» del escritor S. Roncagliolo ${ }^{11}$. En su comparación entre la literatura inglesa y la literatura española de la inmigración, destaca tres etapas en la integración de la temática de inoculación de culturas nuevas en el panorama literario inglés en estos últimos treinta años. Menciona así a Salman Rushdie - por tener una perspectiva ya no autóctona sino mixta-, a Hanif Kureishi -ya que en su obra la perspectiva del que viene de fuera se internaliza en la sociedad de acogida-; y a Zadie Smith -cuya obra se caracteriza por entremezclar las generaciones y los orígenes étnicos hasta rozar lo absurdo-. Frente a esas distintas generaciones, el escritor peruano-español nota muy bien que la situación en el ámbito hispánico es muy distinta ya que en ésta la inmigración parece ser una temática casi ausente. Menciona así a los autores del boom -como Carlos Fuentes o Mario Vargas Llosa- como posibles precursores de una literatura inmigrante por tener la conciencia de ser de otro lugar y tener, a su vez, la facultad de poder contemplar ese lugar con ojos europeos. Según S. Roncagliolo, las generaciones posteriores de escritores latinoamericanos en España -mayoritariamente de clase

\footnotetext{
${ }^{8}$ Benito Del Pliego (ed.), Extracomunitarios. Nueve poetas latinoamericanos en España, Madrid, Fondo de Cultura Económica, 2013.

${ }^{9}$ Nicolás Kanellos, Hispanic literature of the United States: a Comprehensive reference, Westport, Greenwood Press, 2003; e Hispanic Immigrant Literature: El Sueño del Retorno, Austin, University of Texas Press, 2012.

${ }^{10}$ Pauline Berlage, «La paradoja de la literatura de la migración latinoamericana contemporánea: algunas reflexiones a partir de la obra de Juan Carlos Méndez Guédez», en Luigi Giuliani, Leonarda Trapassi \& Javier Martos (eds.), Lejos es aquí/Far Away is Here, Berlín, Frank and Timme, 2014.

${ }^{11}$ Santiago Roncagliolo "Los que son de aquí. Literatura e inmigración en la España del siglo XXI», Quórum, 19, 2008, pp. 150-167.
} 
media $^{12}$ - no siguieron desarrollando esta perspectiva al usar el cosmopolitismo como marca de fábrica y como respuesta al «exotismo latinoamericano» ${ }^{13}$. Así pues, muchos escritores latinoamericanos, como los de la generación del crack, han rechazado el componente exótico para presentarse como un pueblo más de la aldea global ${ }^{14}$.

A pesar de percibir la ausencia de la literatura que trata el tema de la inmigración en España, el escritor nota también que esta corriente se está desarrollando muy paulatinamente. Cinco años más tarde, ésta ya es mucho más visible y podríamos mencionar a muchos más autores como Inés Fernández Moreno, Flavia Company o Fernando Iwasaki, entre los más populares, junto a obras que no tuvieron tanto eco como fue el caso de La paz de los vencidos de Jorge Eduardo Benavides publicada en 2009.

Desde América Latina, algunos teóricos ya habían destacado esta temática, uno de los primeros críticos en interesarse en el corpus de la literatura de la migración latinoamericana como encrucijada de temas literarios es A. Cornejo-Polar desde su experiencia peruana ${ }^{15}$. El teórico andino explica que ve en la categoría «literatura de la migración» una posibilidad de lectura de un amplio corpus, poco atendido, al reunir temas muy variados como el del desarraigo y el de la subalternidad, pero también el de los éxitos y logros personales y colectivos. Define el discurso del/sobre el migrante por la fluidez de su itinerario a través de tiempos y espacios distintos en el que se superponen y se refunden las vivencias del inmigrante lo que permite vincular polos supuestamente opuestos como la nostalgia contra el triunfo o la construcción contra la reafirmación de identidades. La característica principal de este tipo de discurso es, según el académico, un descentramiento continuo ya que acoge varias experiencias de la vida sin necesidad de síntesis -o transculturación- armónica. Por tanto, a diferencia del crítico poscolonial Néstor

\footnotetext{
${ }^{12}$ Para explicar la ausencia de la temática de la inmigración en la literatura española, S. Roncagliolo precisa también que la inmigración en España apenas ha cumplido quince años y que, además, sigue siendo muy regulada por el Estado que solo acoge a individuos de la clases media -susceptibles de integrarse más fácilmente-. Una situación muy distinta de la de la isla británica que ha acogido a inmigrantes desde más de medio siglo, inmigrantes que se han insertado en todas las clases (ibid.). Cabe subrayar que, al día de hoy y a raíz de la crisis económica mundial, la legislación española empuja claramente el retorno de la mayoría de los inmigrantes que vivían en el país.

${ }^{13}$ Santiago Roncagliolo, art. cit., p. 157.

${ }^{14}$ En este sentido la antología McOndo (1996) es, creo, el ejemplo paradigmático.

15 Antonio Cornejo-Polar, «Una heterogeneidad no dialéctica: Sujeto y discurso migrantes en el Perú Moderno", Revista Iberoamericana, 62, 176-177, 1996, pp. 837-844.
} 
García Canclini, que a partir de los flujos migratorios contemporáneos, celebra la desterritorialización ${ }^{16}$, A. Cornejo-Polar ve en estas narrativas un discurso múltiplemente situado ya que hablan a la vez desde un ayer y un hoy y de un aquí y un allí.

Así pues, han empezado a florecer distintas apelaciones propuestas tanto por los críticos como por los escritores mismos para referirse a esta ficción plasmada allá/acá. De esta forma, el profesor Marco Kunz, al tratar la escritura de Juan Carlos Méndez Guédez, habla de «escritura migrante» dentro del panorama de la literatura migrante española ${ }^{17}$.A. De Chatellus también se ha referido a la escritura del autor venezolano español como «escritura líquida» por ser una escritura en la que se disuelven fronteras. Según la crítica francesa, las fronteras que separan las historias son a la vez culturales, espaciales y formales, aunque al final opina que las obras del venezolano-español dejan al lector frente a una escritura universal en lengua española ${ }^{18}$. Pero aunque los puntos abordados en este artículo suscitan mucho interés, no queda claro en qué medida estos rasgos difieren de escrituras contemporáneas en las que se suele mezclar géneros literarios o temporalidades.

Por su parte, muchos de los escritores en esta posición binacional -o transnacional- también han reaccionado frente a la posición y al papel que se les atribuían como escritor de la (in)migración. Así pues, Andrés Neuman explicó que después de la dicotomía entre los que hablaban de su país -se refiere a los escritores del boom- y la generación del Crack que siempre se ha negado escribir sobre cualquier tema que tenga que ver con su país, hemos entrado en otra etapa en la que se trata de escribir sobre su país pero con la perspectiva de un extranjero. Según el escritor argentino-español, en la literatura latinoamericana actual escrita en el extranjero, ya no se trata de expresar una esencia sino de localizar la extranjería de su país de origen, y cita Historia secreta de Costaguana de Juan Gabriel Vásquez como ejemplo paradigmático ${ }^{19}$. Así pues, entre los

\footnotetext{
${ }^{16}$ Néstor García Canclini, Latinoamericanos buscando lugar en este siglo, Buenos Aires/ Barcelona/México, Paidós, 2008.

${ }^{17}$ Marco Kunz, «Barquisimeto global. La narrativa migrante de Juan Carlos Méndez Guédez», Aleph, 25, 2012, pp. 35-44.

${ }_{18}$ Adelaide De Chatellus, «La escritura líquida de Juan Carlos Méndez Guédez», Letral, 7, 2011, pp. 59-65, www.proyectoletral.es/revista/descargas.php?id=115 [01-04-2016].

${ }^{19}$ Andrés Neuman, «Encuentro con Andrés Neuman en el sminario 'Lieux \& figures du déplacement: Le sujet migrant'», Université de Lille III, 2011 (9 de noviembre), (sin publicar).
} 
meta-discursos de los mismos escritores inmigrantes hispanoamericanos -de primera o segunda generación- que viven ahora en España, encontramos términos como el de "literatura de inquilinos», propuesto por Juan Gabriel Vásquez, o el de los escritores «garcilasos», usado ya varias veces por Fernando Iwasaki ${ }^{20}$.

Estas distintas comprensiones de la literatura de la migración muestran así las dificultades que cualquier crítico encuentra a la hora de definir su objeto de estudio: ¿Qué es lo que entendemos por «migrante»? ¿Estamos hablando de un escritor o de un mundo descrito en la novela? Más generalmente nos preguntamos también si tal etiqueta es válida en un mundo cultural globalizado. La denominación podría, de hecho, mantener una antigua división colonial, nacional, étnica o sexual. En este caso, clasificar a algunos autores bajo la etiqueta de literatura de la migración podría preservar la división actual entre literatura nacional, mundial, étnica o latinoamericana "auténtica», en la que el marketing editorial parece arraigarse.

\section{Nuevo corpus, nueva mirada}

Para contestar a esas preguntas, me centraré aquí en cinco aspectos importantes en la delimitación de un corpus de la literatura de la migración: destacaré primero la confusión tramposa que surge a menudo entre narrador, personaje y escritor migrante; luego definiré el lugar que ocupa la literatura de la migración frente a la del exilio; trataré, a continuación, las temáticas que el género de la literatura de la migración abarca y los rasgos estilísticos que estas obras suelen compartir; y, finalmente, me interesaré por nuestro papel de lector(a) de esas obras literarias transnacionales.

Un primer paso en mi definición del corpus de textos que llamo «literatura de la migración» es el de aclarar el entrecruzamiento de las nociones de personajes, de narrador y de autor migrantes. Puesto que la locución «literatura migrante» puede referirse tanto a los autores como a las obras que evocan esta temática, la confusión puede llevarnos a considerar la ficción escrita por estos autores como testimonios o documentos.

${ }^{20}$ Fernando Iwasaki, Mi poncho es un kimono flamenco, Lima, Sarita Cartonera, 2005. 
Constato, de hecho, que la mayoría de las obras latinoamericanas de la segunda parte del siglo Xx que tratan el tema migratorio fueron escritas por autores que emigraron o son descendientes de emigrantes. Las novelas tan distintas entre sí como lo son Salsa, de C. Obligado; Le retour, de A. Manguel; o Memorias de una dama, de S. Roncagliolo son todas obras de escritores migrantes, de un país latinoamericano a Europa -la gran excepción que confirma la regla sería Paraíso Travel de Jorge Franco quien no tuvo que inmigrar para escribir su novela-. Son pues mayoritariamente escritores con una experiencia migrante propia los que abordan este tema o motivo literario. De allí hay un paso que no daré ya que no se trata de considerar las obras de ficción como creaciones marcadas de punta a punta por la experiencia personal del escritor. Aunque algunas obras sí cultivan paralelos con la vida del autor se trata de destacar que las experiencias migratorias pueden haber abierto una brecha, y de subrayar en qué manera los escritores abren la literatura a nuevos temas y nuevas formas de escritura.

Otro punto que cabe precisar concierne el proceso transnacional contemporáneo que se distingue, en algunos aspectos, de la literatura del exilio. Hoy día, es un truismo afirmar que vivimos en un mundo globalizado y en una época de movimientos de población incesantes, ya sea de comunidades en exilio, de migración económica o política, o de diásporas. Empero, siempre resulta peligroso separar claramente el exilio político de la migración «económica» y, a partir de esto, dividir la producción cultural en dos campos distintos. En efecto, puesto que la decisión de migrar se sitúa siempre en un continuo «migración forzada - migración voluntaria» no exclusivo, varios críticos ya han cuestionado la validez de este cambio de paradigma de una literatura del exilio a una literatura de la migración ${ }^{21}$. Está claro que desde los puntos de vista tanto de la crítica literaria como de la producción literaria -escrita por autores que se mueven de un país a otro y cuyas obras son publicadas en editoriales situadas, a veces, a miles de kilómetros de su país de origen-, el proceso de globalización cultural es ahora una evidencia que se ha de tomar en cuenta en cada nivel del análisis del campo literario. Pero si cada vez hay un número mayor de personas que estamos de acuerdo sobre el hecho de

${ }_{21}$ Carina Mardorossian, «From Literature of Exile to Migrant Literature», Modern Language Studies, 32.2, 2002, pp. 15-33. 
que la frontera no nos separa de los «extranjeros», sino que se establece para separar los lugares seguros de los inseguros y, de esta manera «distinguirnos a nosotros de ellos» como lo afirmó G. Anzaldúa ${ }^{22}$, sigue siendo arriesgado delimitar lo que E. Said llamó «el territorio peligroso de la no pertenencia». Si el crítico se refería sobre todo a los exiliados, este «no territorio» también es el lugar errante de los refugiados, de los deportados y de los migrantes y, por ende, de la literatura escrita por/sobre ellos.

C. Mardorossian afirma que una de las características de la literatura de la migración es de sobrepasar el sistema binario presente en muchos relatos del exilio que se fundamenta en una dualidad entre un acá alienante y una allá idealizado ${ }^{23}$. Asimismo, me parece que la literatura de la migración nos permite ver el desplazamiento desde otro paradigma, cuya matriz es la re/de-construcción constante de las subjetividades, su búsqueda imparable, o lo que otros llamaron "descentramiento» ${ }^{24} \mathrm{o}$ «bipolaridad» $»^{25}$. Esto nos lleva, pues, a la cuestión de las numerosas temáticas que abarcan este género amplísimo.

La característica más importante de este corpus heterogéneo es la de tratar la redefinición de ciertas subjetividades en paralelo al movimiento en términos geográficos. Este desplazamiento es también identitario ya que impulsa a la vez una evolución de las subjetividades e impone una reconstrucción cultural inevitablemente híbrida. Los textos de literatura de la migración son obras en contraste entre, por lo menos, dos culturas -siendo una el lugar de origen y la otra, el lugar de residencia-, a través de sus reflexiones creativas y críticas, estas obras tratan de visiones inciertas, cambiantes, pero también esclarecedoras acerca de identidades «glocales» ${ }^{26}$.

S. Frank, en su publicación Migration and literature, propuso una lista de temas globales y de rasgos formales comunes a todas las obras de la migración. Así pues, desde un punto de vista temático, esta literatura se

\footnotetext{
${ }_{22}$ Gloria Anzaldúa, Borderlands/ La frontera. The new mestiza, San Francisco, Aunt Lute Books, 1999.

${ }^{23}$ Carina Mardorossian, art.cit.

${ }^{24}$ Antonio Cornejo-Polar, art.cit.

${ }^{25}$ Marco Kunz, art.cit.

${ }^{26}$ Se trata de una haplología anglosajona que juega con las palabras "global» y «local», Robertson fue el primero en hablar de glocalization refiriéndose al interés de los estudios poscoloniales en los modo en los que lo global está transformado a un nivel local (Cfr. Roland Robertson, «Glocalization:TimeSpace and Homogeneity-Hterogeneity", en Mike Featherstone, Scott Lash \& Roland Robertson (eds.), Global Modernities, London, Sage, 1995, pp. 25-44).
} 
dedicaría a la cuestión identitaria -ya sea humana, cultural o nacional- y al proceso de globalización que la atañe, que puede ser destructivo o doloroso pero también fascinante ${ }^{27}$. En este ámbito, muchas de esas obras funcionarían como reescritura de la identidad con el fin de evocar su carácter necesariamente impuro y heterogéneo. En cuanto a su forma estilística, la literatura de la migración se destacaría especialmente por la multiplicidad de líneas narrativas, de discursos y de estilos, de perspectivas y también de lenguajes. Por tanto, Soren Frank ve la literatura de la migración como una encarnación paradigmática del concepto de «heteroglosia» de Bajtín y un modo de resaltar el constructivismo del mundo actual ${ }^{28}$.

Desde luego, esta teorización es muy valiosa a la hora de circunscribir la literatura de la migración latinoamericana; el crítico danés no se pierde en subcategorizaciones inútiles al destacar los puntos clave de una literatura en emergencia. Sin embargo, me consta que el literato no resalta lo suficiente la dimensión poscolonial desarrollada en muchas de esas obras de ficción, ni tampoco tiene en consideración las implicaciones sociales y materiales de esas obras al descartar los temas de género, etnicidad y clase.

Roy Sommer también reflexionó sobre las particularidades de la Migration literature y estableció una clasificación en la que diferencia las novelas multiculturales de las transculturale ${ }^{29}$. El primer tipo atendería a la temática de la variedad de los flujos culturales y de la no pertenencia como un problema al quitar la estabilidad y el arraigamiento necesarios a los individuos. Dentro de esta categoría encontraríamos la novela de la migración -que relata la experiencia diaspórica- y el Bildungsroman multicultural -que trata de los inmigrantes de segunda generación y de su búsqueda de identidad ${ }^{30}$ - La novela transcultural, por su parte, celebraría el desarraigo y la fragmentación cultural como procesos liberadores que permiten una identidad en constante devenir. El profesor alemán subdivide esta categoría en dos subgrupos: la novela histórico-revisionista -que

\footnotetext{
${ }^{27}$ Soren Frank, Migration and Literature. Günter Grass, Milan Kundera, Salman Rushdie, and Jan Kjarstad, New York, Palgrave, 2008.

28 Soren Frank, op. cit., p. 20.

29 Roy Sommer, Fictions of Migration. Ein Beitrag zur Theorie und Gattungstypologie des zeitgenössischen interkulturellen Romans in Grossbritannien, Trier, Wissenschaftlicher Verlag Trier, 2001.

${ }^{30}$ Roy Sommer, op. cit., p. 75.
} 
deconstruye la historia colonial desde ángulos de múltiples perspectivasy la novela híbrida transcultural -que presta atención a la hibridez, entre otros aspectos, de las identidades culturales.

Esta ordenación de la literatura, aunque permite organizar un campo de estudio muy vasto, obliga al lector a centrarse en un aspecto preciso de una novela que bien podría pertenecer a dos o más de esas categorías. Nos quedaremos, por tanto, con motivos como el del Bildungsroman, la necesaria hibridez o la revisión histórica en calidad de «lugares de arraigamiento", pero sin considerarlos excluyentes.

Desde un punto de vista de la forma específica de la literatura de la migración, sería lógicamente imposible y estéril resumir la forma que pueden tomar las obras de la migración. Además de los aspectos mencionados anteriormente al resumir las propuestas de S. Frank y a R. Sommer, solo apuntaré algunas características más, refiriéndome a los distintos puntos comunes entre algunas novelas de la migración en Italia mencionados por Sabelli: «Cultural contamination, linguistic hybridization, an intense connection with the rhythm of oral speech [...], and a strong presence of irony that is the result of multiple points of view» ${ }^{31}$.

Aunque las características enunciadas aquí son puntos que también encontramos en muchas de las obras (de narrativa) latinoamericanas contemporáneas que no tratan necesariamente de la migración, me parece que la hibridez lingüística y cultural que encontramos, por ejemplo, bajo la forma de préstamos léxicos y referencias culturales, variadas e incesantes, es una característica constituyente de este tipo de literatura. El hibridismo lingüístico es constante y continuo, algo que surge de manera natural en estas obras de la migración. Por tanto, entendemos, y con razón, por qué destaca Sonia Sabelli la contaminación cultural, el ritmo oral de esta narrativa y la ironía como puntos comunes entre las obras de literatura de la migración latinoamericana; una ironía que se debe, a veces, a la multiplicidad de los puntos de vista.

Finalmente, hay que subrayar el componente dialógico entre el autor y el lector de esas obras de la literatura de la migración tal y como lo hacen L. Lequin y M.Verthuy acerca de la literatura migrante

\footnotetext{
${ }^{31}$ Sonia Sabelli, «Transnational Identities and the Subversion of the Italian Language en Geneviève Makaping, Christiana de Caldas Brito, and Jarmila O kayová», Dialectical Anthropology, 3-4.29, 2005, p. 440 .
} 
quebequense ${ }^{32}$. Asimismo, me consta que el diálogo de lectura y escritura entre los lectores y el/los narradores de las novelas de literatura de la migración es muy rico, y constituye una relación activa y original de lectura del mundo. Se pone de relieve, cada vez más, la posición primordial del lector en la comprensión de una obra: Linda Hutcheon habla así de "comunidades discursivas» para subrayar el imprescindible papel del lector en la lectura, una «actividad hermenéutica participativa»" ${ }^{33}$, una comprensión de la lectura que coincide con perspectivas críticas como la semiología textual de M. Ezquerro $^{34}$. Las obras de literatura de la migración favorecen, pues, esta lectura activa por parte de los lectores quienes, al leer, cuestionan su cultura y la cosmovisión personal que han ido desarrollando desde sus primeras lecturas.

De todo lo dicho hasta ahora puede concluirse que el enfoque que permite el término "literatura de la migración» tiene varias razones de ser. Así pues, en la producción literaria que trata el tema de la migración transnacional, este término muestra que se centra en las obras que abarcan el tema de la inmigración desde la perspectiva del país de llegada o de paso. He preferido este término al de «literatura migrante» ya que éste no enfatiza suficientemente la perspectiva de adaptación/cuestionamiento que implica la llegada y la instalación a un nuevo país -una perspectiva que, desde luego, tampoco consigue transmitir la expresión «literatura de la emigración».

Por lo tanto, si he hablado de obras como las de Juan Carlos Méndez Guédez, Carlos Liscano y Junot Díaz ${ }^{35}$ como obras pertenecientes a un corpus de literatura de la migración es porque creo que dichas novelas cuestionan esas nociones de identidad, multiculturalismo ${ }^{36} \mathrm{y}$

\footnotetext{
${ }^{32}$ Lucie Lequin \& Maï Verthuy, Multi-culture, Multi-écriture. La voix migrante au féminin en France et au Canada, Paris/ Montréal, L'Harmattan, 1996, p. 3.

${ }^{33}$ Linda Hutcheon, Irony's Edge: the theory and politics of irony, London/ New York, Routledge, 1994, p. 96.

${ }_{34}$ Milagros Ezquerro, Fragmentos sur le texte, Paris, L'Harmattan, 2002.

${ }^{35}$ Pauline Berlage, Las políticas de representación del género en la escritura de la migración latinoamericana. Un análisis comparativo de El camino a Ítaca, de C. Liscano; Árbol de Luna, de J. C. Méndez Guédez; y The Brief Wondrous Life of Oscar Wao, de J. Díaz, Universitat Autònoma de Barcelona/ Université François Rabelais de Tours, 2014, http://www.tdx.cat/bitstream/handle/10803/145391/pb1de1.pdf; jsessionid=F904AEAA3BD495ADACE411F37F7ABD55.tdx1?sequence=1 [01-04-2016].

${ }_{36}$ Aunque el término «multiculturalismo» no me satisface totalmente, ya que insinúa una distinción clara y, quizás, esencialista entre las diferencias, lo seguiré usando aquí porque permite transmitir los avances y la potencialidad de prácticas y conocimientos comunes así como los límites de éstos.
} 
representaciones de lo Otro. Estos replanteamientos funcionan siempre en un movimiento sin cesar de idas y venidas entre una comprensión local del mundo y los cuestionamientos de la literatura global. Así pues, la literatura de la migración no es un corpus de textos que tiene que haber sido escrito por autores inmigrantes ya que nos centramos en la ficción y en las voces narrativas. Esas obras pueden tratar pues de la migración de personajes inmigrantes - de primera generación- al igual que de las consecuencias de esta relocalización para las siguientes generaciones. Esos textos abordarán los motivos de la salida del país, del viaje y del establecimiento en el nuevo país; y en la ciudad de residencia abordará, más concretamente, el aprendizaje de un idioma, la búsqueda de un trabajo y la construcción de un nuevo hogar, entre muchos otros.

No obstante, como bien dicen S. Ponzanesi y D. Merolla en su introducción de Migrant Cartographies, subrayar estas nociones sin ligarlas a temas de género, etnicidad, clase y nacionalidad significaría perder las implicaciones sociales y materiales de esos textos ${ }^{37}$. Por tanto, aunque son centrales en el área de los estudios culturales de las migraciones, no me refiero aquí a los intelectuales trotamundos ${ }^{38}$ sino al material literario mismo desde un punto de vista interseccional -en términos de género, de clase y de origen étnico.

\section{Una «mundialidad» hispánica}

Al vivir, hoy en día, en un mundo globalizado, en una época de movimientos de población incesantes, sea desde los puntos de vista de la producción o de la crítica literaria actual, es cada vez más utópico querer estudiar una realidad local desconectada del resto del mundo. El debate acerca de la literatura posnacional lo demuestra muy bien: a partir de los trabajos de E. Said, de U. Beck o de J. Habermas algunos críticos han demostrado el desfase entre un discurso literario nacional y la realidad política, económica y sociocultural actual que impide seguir pensando en el marco restringido de un país. La perspectiva ha de ser mucho más

\footnotetext{
${ }^{37}$ Sandra Ponzanesi \& Daniela Merolla, Migrant Cartographies. New Cultural and Literary Spaces in PostColonial Europe, Lanham, Lexington Book, 2005, p. 3.

${ }^{38}$ Pienso, por ejemplo, en Una luna, diario de un hiperviaje de Martín Caparrós (2009) o en el ensayo reciente de Andrés Neuman Cómo viajar sin ver. Latinoamérica en tránsito (2011).
} 
amplia y sistémica, dado que el libro resulta ser un objeto cultural que se ha convertido en un producto transnacional por causa de la globalización.

Desde la vertiente norteamericana, y especialmente la estadounidense, y teniendo en cuenta la historia de este país, las literaturas originarias o las que abarcan el tema de la migración son enormemente abundantes. La explicación de Edward Said acerca de la literatura de la migración es bastante interesante en este contexto. El profesor palestino-americano la define como un género literario al que varios escritores de la posguerra (mundial) han contribuido. Cita, por ejemplo, los nombres del escritor checo-francés Milán Kundera, el deV.S. Naipul -de nacionalidad británica pero de origen trinitense-hindú- y del autor indio nacionalizado británico, Salman Rushdie ${ }^{39}$.

Estos escritores han escrito obras cuya posición cultural e histórica es específica, pero comparten un conjunto de articulaciones informales y conforman así un mundo literario. Said subraya de esta manera la «mundialidad $»^{40}$ de la literatura migrante, la cual se aleja de la literatura regional separatista y exclusiva, en la que cada una de esas obras sería un espécimen etnográfico instructivo -interesante solo para los especialistas- ${ }^{41}$. No obstante, Said no define específicamente lo que entiende por literatura de la migración, solo enfatiza la importancia de situar a estos autores en el contexto global de literatura mundial y en la cultura humana en general.

Acerca de la literatura hispánica, el crítico uruguayo-español Fernando Aínsa se basa en un sentido de amplitud similar al de Said para abolir las categorías entre literatura nacional y de emigración, que no tienen ningún sentido para él en un mundo tan intercomunicado e interdependiente como el nuestro. En su artículo «Palabras nómadas. La patria a distancia y el imposible regreso", F. Aínsa explica así que el arte no tiene patria, pero el escritor sí, la literatura es pues un puente entre límites borrosos que se pueden esencializar para, paradójicamente, lograr una universalidad plena ${ }^{42}$. El escritor uruguyao-español cuestiona, por tanto, la división de las obras latinoamericanas en función de etiquetas nacionales, perspectiva compartida por Claudio Guillén.

\footnotetext{
39 Edward Saïd, Réflexions sur l'exil et autres essais, Paris, Actes Sud, 2008, p. 492.

40 Traducción del concepto de «worldliness» por Nora Catelli en Cultura e imperialismo (2005).

41 Edward Saï, op. cit., p. 493.

42 Fernando Aínsa, "Palabras nómadas. La patria a distancia y el imposible regreso», Letral, 5 http://www.proyectoletral.es/revista/\#void [01-04-2016].
} 
En su ponencia titulada «Los equívocos de la identidad cultural» ${ }^{43}$ el catedrático español explica que un mismo escritor puede pertenecer a varias culturas a la vez y que «ninguna cultura es monolítica», como decía ya Said, antaño colega suyo. En su intento de clarificar los términos de «identidad» y de "cultura», dos conceptos ambiguos y malentendidos, Guillén afirma que lo importante y prioritario hoy es «la perspectiva histórica, la percepción de continuidades y discontinuidades, la inteligencia del devenir, que se compadece mal con la esencialidad que estorba gravemente el discurso sensato de la identidad [única]»" ${ }^{44}$. Para ello, tenemos que pasar por un encuentro con la literatura ya que el saber acerca de las letras o literaturas propias es «un proceso paulatino de autoconocimiento", añade el académico. La tarea de los críticos es pues la de descubrir y ordenar esta abundante y diversa literatura. Guillén concluye así que en esta gran «aventura intelectual de integración», el concepto de literatura nacional ya no es válido, y ya tampoco lo es la separación entre los creadores de la Península Ibérica y los latinoamericanos. Hoy día, todos forman ya una comunidad que representa la unidad en la pluralidad y la pluralidad en la unidad según Claudio Guillén.

La literatura de la migración, producción literaria transatlántica, vuelve pues a desdibujar un poco más el concepto ya opaco de "Latinoamérica» vs. «España». En su ensayo Latinoamericanos buscando lugar en este siglo, Nestor García Canclini da muy buena cuenta de los cuestionamientos actuales sobre la validez y la viabilidad de lo que llamamos «Latinoamérica». N. García Canclini explica que hay cada vez más respuestas negativas a la pregunta «¿quién quiere ser latinoamericano?». Según N. García Canclini, actualmente se habla de América Latina como conjunto principalmente a nivel de producción cultural, de deuda o de migración. Subraya que uno de los tres modos de globalizar este enorme continente es, pues, con el fenómeno mismo de la migración. Simplificando sus palabras, podríamos decir que "lo latinoamericano» nace justamente cuando los seres dejan su país, y desde fuera, a estos seres tan distintos, originarios de países tan diferentes, los encasillamos en una categoría general llamada "América Latina».

\footnotetext{
${ }^{43}$ Claudio Guillén, «Los equívocos de la identidad cultural», 2004, http://congresosdelalengua.es/ rosario/plenarias/guillen_c.htm [01-04-2016].

${ }^{44}$ Claudio Guillén, art. cit.
} 
Vemos que el mismo concepto de arte o literatura «latinoamericana» solo funciona en binaridad frente a otro concepto u otro adjetivo, como «europeo", «español»o "estadounidense» un mecanismo ya destacado por Jacques Derrida bajo la apelación de «lógica de suplemento» o del «afuera constitutivo» en De la gramatología y retomado por Butler en Bodies that Matter (1993). Empero, me parece que tampoco podemos concluir que todas las obras contemporáneas de narrativa de la inmigración -la producción literaria que nos ocupa aquí- pertenecen a una misma masa indefinida y a-histórica de literatura, como lo sugieren algunas páginas web de librería en línea. La mayor parte de esas obras tratan o bien de una inmigración en la madre patria de la época de la colonia, España, o de la inmigración en el país cuya cultura es una de las mayores culturas "colonizadoras» hoy día en Latinoamérica: Estados Unidos.

Estas reflexiones nos llevan, inevitablemente, a pensar en las implicaciones de tipo poscolonial de la literatura de la migración latinoamericana. De hecho, aunque las relaciones de poder -desde un punto de vista histórico y del marketing editorial- entre la literatura latinoamericana y la literatura española, por una parte, y la literatura latinoamericana y la literatura estadounidense, por otra parte, no sean iguales, está claro que la producción literaria latinoamericana de la inmigración se sitúa en interacciones culturales poscoloniales.

De hecho, la mayoría de los escritores inmigrantes vienen de las colonias -antiguas o contemporáneas- fruto de la colonización brutal de la extensión del Imperio Español o de la más pacífica pero insidiosa homogeneización cultural estadounidense. Los movimientos migratorios entre Latinoamérica y Europa siguen, pues, el camino de vuelta de los galeones de la colonia al regresar a la metrópoli. Empero, la diferencia fundamental es que mientras en el momento de la colonización, los viajes hacia América nunca fueron considerados como migración, ahora estos viajes de vuelta sí lo son -con todos los prejuicios que el término «inmigrante» implica actualmente ${ }^{45}$ - Paralelamente, la situación actual entre varios países latinoamericanos y Estados Unidos son claramente un

\footnotetext{
${ }^{45}$ En este marco, cabe subrayar la paulatina evolución del mercado editorial hispánico que, desde hace unos años, se está desplegando especialmente en las grandes urbes latinoamericanas, como ya lo apuntó J. Casamayor de la editorial Páginas de Espuma (Juan Casamayor, «Militancia, insumisón y otras delincuencias latinoamericanas", Letral, 5, 2010, pp. 14-18, http://www.proyectoletral.es/revista/ index.php?id_num=6 [01-04-2016]).
} 
eco de la colonización desde un punto de vista cultural por ser influencias omnidireccionales e imperialistas.

Esta reflexión nos lleva a cuestionarnos por el estatus de esta literatura. De hecho, como S. Ponzanesi y D. Merolla se lo preguntan en la introducción de su ya citado estudio sobre la literatura de la migración en Europa, la pregunta más espinosa en esta discusión es la de entender si la misma noción de migrante no representa solo al trotamundos sino también a la persona que reproduce la división colonial en nuevos términos ${ }^{46}$. De hecho, el término «inmigrante» significa el que «no pertenece a esta tierra». Dicho término se puede utilizar, entonces, para marcar la diferencia étnica -lo exótico y la «otredad»-incluso en términos literarios. Por esta razón, la literatura de la migración se relega, a veces, a la literatura étnica, cuyo efecto pernicioso y paradójico es el de encerrar esta literatura transnacional en un "gueto cultural».

En contraposición, ciertos críticos han rechazado el principio mismo de canon literario puesto que clasifica la producción literaria en función de unos criterios obsoletos nacionales, entre otros muchos. La mayoría de los escritores contemporáneos son, de hecho, transnacionales y no se limitan a una forma, a un estilo, a un género literario tradicionalmente asociado a un país o a una región única -como la picaresca o lo real maravilloso-. En este caso se podría pensar que el término de «literatura de la migración» es redundante, si no, preciso que lo uso, precisamente, para destacar autores que rechazan la idea de apropiación literaria y que están vinculados a una genealogía de la inmigración.

Estas cuestiones están en el centro de interés de numerosos críticos poscoloniales como Homi K. Bhabha. En The Location of Culture, H. K. Bhabha deconstruye el pensamiento identitario dialéctico basado en el 'mismo' versus el 'otro' para proponer una lógica posestructural de la hibridez. Así, Bhabha no habla de cultura sino de «enunciaciones culturales», y cada una de ellas está pensada desde diferencias internas como el sexo, la clase o la raza $-y$ añadiré el género ${ }^{47}-$. Los contactos entre esas producciones no son, pues, choques entre culturas sino procesos de negociaciones y traducciones entre culturas heterogéneas. Esta perspectiva me parece enriquecedora al subrayar que se trata de una literatura que

46 Sandra Ponzanesi \& Daniela Merolla, op. cit.

47 Homi K. Bhabha, Les lieux de la culture: Une théorie postcoloniale, París, Payot \& Rivages, 2007. 
vuelve a plantear los límites impuestos, cuestiona las codificaciones y obliga a negociar las diferencias ${ }^{48}$.

Por tanto, si la literatura de la migración no es reciente, lo es, en cambio, el reconocimiento de la hibridez cultural de la literatura de un espacio geográfico dado. Por esta razón, solo hablo aquí de literatura de la migración en esta perspectiva, la que subraya los aportes de los escritores extranjeros en un corpus nacional, un corpus que solo existe gracias a la riqueza de intercambios, influencias y mezclas variadas.

Pauline BerLAge

Université de Liège

\footnotetext{
${ }^{48}$ Mi lectura de las novelas de J. C. Méndez Guédez, C. Liscano y J. Díaz se propuso definir más precisamente la transversalidad de esta poética de la migración destacando los modelos y tópicos literarios y de género hegemónicos, las normas nacionales y diaspóricas de género así como las construcciones espaciales genéricas de dichas obras de ficción (Berlage, op. cit., 2014).
} 